\section{As fricativas posteriores: caracterização articulatória e acústica do /r/ em onset silábico* กั}

Posterior fricatives: articulatory
and acoustic characterization of
/ $/$ / in syllabic onset

Carine HAUPT (UFT) carineh@uft.edu.br

Izabel Cristine SEARA (UFSC/CNPq**) izabel.seara@ufsc.br

Recebido em: 30 de out. de 2019. Aceito em: 23 de fev. de 2020.

*Pesquisa financiada pela Coordenação de Aperfeiçoamento de Pessoal de Nível Superior - CAPES. ** Processo n. 308066/2018-9.

ca

acústica do /r/ em onset silábico.

Resumo: O presente estudo é um esboço inicial da caracterização articulatória e acústica de fricativas posteriores na posição de onset silábico. São poucos os estudos que utilizam recursos, como parâmetros acústicos, para confirmar as impressões de oitiva da produção das fricativas posteriores (SILVA, 2002; REINECKE, 2006; RENNICKE, 2015). Assim, este trabalho tem o objetivo de apresentar características articulatórias de fricativas posteriores a partir de imagens ultrassonográficas e, posteriormente, discutir dois parâmetros acústicos: picos espectrais e amplitude. A amostra se constitui da gravação de vídeos ultrassonográficos da produção de fricativas por duas informantes da cidade de Florianópolis. O corpus contém palavras reais e pseudopalavras, nas quais foi controlado o contexto vocálico ([a, i, u]). Para as análises, foram utilizados o software Articulate Assistant Advanced, a partir do qual foram observados os movimentos da língua em cada fricativa produzida; e o Praat, para as análises acústicas. Os resultados das imagens mostram constrições na região velar e faringal, condicionadas às vogais adjacentes: fricativas velares e faringais ocorreram apenas em contexto de [a], 
V. $10(1)$ 77-97 jan-abr 2020 enquanto, para os demais contextos, foram encontradas fricativas glotais. Em nossos dados, a amplitude se mostrou um parâmetro significativo para distinguir as fricativas posteriores, e os picos espectrais encontram-se em frequências mais altas para as velares do que para as faringais e seguem o padrão das vogais para as glotais. Todavia, consideramos necessários mais estudos para maiores generalizações.

Palavras-chave: Fricativa posterior. Ultrassonografia. Acústica.

Abstract: The present work is an initial outline of the articulatory and acoustic characterization of posterior fricatives in the syllabic onset position. There are few studies that use resources, such as acoustic parameters, to confirm the eighth hearing impressions of the production of later posterior fricatives (SILVA, 2002; REINECKE, 2006; RENNICKE, 2015). Thus, this work aims to present articulatory characteristics of posterior fricatives from ultrasound images and, later, to discuss two acoustic parameters: spectral peaks and amplitude. The sample of this study is composed of the recording of ultrasound videos of two informants from the city of Florianópolis. The corpus contains real words and pseudowords, in which we control the vowel context $([a, i, u])$, and were repeated 5 times by each informant. For the analyses, we used the Articulate Assistant Advanced software, from which we observed the movements in each segment, and Praat for the acoustic analyses. The results of the images show constrictions in the velar and pharyngeal region, conditioned to the adjacent vowels: velar and pharyngeal occur only in the context of [a], while for the other contexts we find glottal. In our data, amplitude proved to be a significant parameter to distinguish posterior fricatives, and also spectral peaks are at higher frequencies for velars than for pharyngeals and follow the pattern of vowels for the glottals. However, we consider further studies necessary are needed for further generalizations.

Keywords: Posterior Fricative. Ultrasonography. Acoustics.

\section{Introdução}

As fricativas posteriores $[\mathrm{x}, \mathrm{\gamma}, \mathrm{x}, \mathrm{b}, \mathrm{h}, \mathrm{h}]$ fazem parte do conjunto de possibilidades de produção dos róticos nas diferentes variedades do português brasileiro (PB), que ocorrem em posição de onset silábico. Muitos estudos já feitos sobre os róticos (HORA; MONARETTO, 2003; BRESCANCINI; MONARETO, 2008; BOTASSI, 2011) partem de impressões de oitiva para classificar a variante de determinada comunidade, outros (SILVA, 2002; REINECKE, 2006; RENNICKE, 2015) sustentam sua classificação a partir de parâmetros acústicos, considerando dados espectrográficos desses róticos. Além disso, na maior parte dos estudos, o foco recai sobre o rótico em posição de coda, e os espectrogramas são usados para diferenciar tepes, retroflexos, aproximantes e fricativas, sem detalhamento maior de características acústicas dessas últimas. Para as fricativas anteriores $[\mathrm{f}, \mathrm{v}$, s, $\left.z, \int, 3\right]$, por sua vez, já há uma vasta gama de estudos acústicos (SILVA, 2012; FERREIRA-SILVA; PACHECO, 2012; CRISTOFOLINI, 2013; CORRÊA, 2013; FERREIRA-SILVA; PACHECO; CAGLIARI, 2015), nos quais se discutem diversos parâmetros, tais quais: picos espectrais, momentos espectrais (centro de gravidade, variância, assimetria, curtose), transição formântica, 
duração e amplitude. Não encontramos, até o momento, descrições em que se analisem especificamente parâmetros acústicos para descrever as fricativas posteriores no PB. Para o português europeu (PE), há o estudo de Jesus e Shadle (2005), no qual os autores investigam a realização de fricativas alveolares ao lado de fricativas uvulares, em posição de ataque e coda. Assim, a escassez de descrições acústicas das fricativas posteriores no PB motivou-nos a escolher essas fricativas como objeto de estudo, a fim de contribuir para a descrição fonético-acústica desses segmentos. Delimitamos o estudo à ocorrência dessas fricativas em onset silábico, tanto em inicial (rato, por exemplo) quanto medial (carro, por exemplo). A realização de fricativas em posição de coda será objeto de trabalhos futuros.

Tendo em vista que as fricativas são uma categoria na qual se encontram muitas variações interindividuais, o que por vezes dificulta sua categorização a partir de critérios apenas acústicos (LADEFOGED; MADDIESON, 1996), valemo-nos de imagens ultrassonográficas para auxiliar na caracterização desses segmentos. Nessas imagens, observamos o grau de constrição máxima da língua na região central das vogais adjacentes e da fricativa, além de verificar os movimentos do dorso e raiz da língua para distinguir fricativas velares de uvulares e talvez até faringais. No caso das glotais, espera-se apenas o movimento de coarticulação de uma vogal para outra, tendo em vista que essa fricativa é produzida já na glote, sem articulação no trato vocal. Desse modo, durante o percurso da fricativa glotal, não se esperam verificar movimentos de elevação do dorso e da raiz da língua. O foco deste trabalho são, portanto, análises das imagens ultrassonográficas usadas para identificar articulatoriamente as fricativas produzidas, e as análises acústicas, considerando os parâmetros: picos espectrais, média dos espectros (centro de gravidade) e amplitude. Todavia, estudos ultrassonográficos de caráter qualitativo mais detalhados e a incorporação de estudos quantitativos são questões abertas para estudos futuros.

Organizamos o texto que se segue da seguinte maneira: primeiramente, faremos um levantamento sobre o que já se sabe a respeito das fricativas posteriores em termos de descrição fonética, com enfoque nas características acústicas. Nessa seção, apresentamos também, em detalhes, o estudo sobre as fricativas uvulares do PE. Em seguida, apresentamos uma seção para descrever a metodologia adotada na presente pesquisa, trazendo informações a respeito de informantes, coleta e análise de dados. Em seção posterior, apresentamos a descrição e discussão dos resultados, que nos encaminharão para as conclusões, seção que fechará este texto. 
V. 10 (1) 77-97 jan-abr 2020

\section{As fricativas posteriores $[x, \gamma, x, b, \hbar, \varsigma, h, h]$ - caracterização fonético- acústica}

No português, enquanto róticos, as fricativas posteriores podem ser velares, uvulares e glotais ${ }^{1}$. Todas elas têm em comum o fato de serem produzidas com fluxo de ar turbulento passando por um estreitamento em algum momento do trato vocal. O ruído causado pelo fluxo de ar turbulento aparece em um espectrograma como energia aleatória distribuída por uma ampla gama de frequências, e essas frequências dependem do local exato de articulação (LADEFOGED; MADDIESON, 1996). A filtragem acústica do trato vocal em fricativas é feita primeiramente nas frequências de ressonância da cavidade frontal. Quando a constrição é na laringe, têm-se frequências de ressonância mais baixas, como é o caso para as fricativas uvulares e glotais. No entanto, análises via espectrogramas (que fazem uma representação temporal do sinal de fala) não são as mais indicadas para um exame detalhado das características espectrais das fricativas. Para isso, são usados métodos ${ }^{2}$ que fazem uma representação dos espectros de frequência do sinal de fala, como a FFT e o LPC (KENT; READ, 2015; CRISTÓFARO-SILVA et al., 2019). Assim, podemos verificar os picos espectrais para inferir o ponto de articulação. Pesquisadores diversos (JESUS, 2000; JONGMANN et al., 2000) relatam em seus estudos que, em fricativas anteriores, os picos espectrais ocorrem em regiões de frequências mais altas e, em fricativas posteriores, encontram-se picos em frequências mais baixas. Desse modo, uma alveolar, por exemplo, terá seu pico espectral acima de $5 \mathrm{kHz}$, enquanto uma palatal terá picos na faixa de $3 \mathrm{kHz}$. Já uma velar terá seus picos entre $1 \mathrm{kHz}$ e $2 \mathrm{kHz}$. A uvular, por sua vez, pode apresentar picos abaixo de $1 \mathrm{kHz} .^{3}$

Em estudo acústico sobre as fricativas uvulares e alveolares do $\mathrm{PE}$, Jesus e Shadle (2005) observaram que os dois fonemas do português que correspondem aos sons de $\mathrm{r}$ foram frequentemente produzidos

\footnotetext{
${ }^{1}$ Segundo Rennicke (2015), fricativas glotais não costumam ser associadas à classe dos róticos, sendo variantes fricativas de outras categorias, como, por exemplo, o [h] do inglês e o [x] do espanhol.

${ }^{2}$ FFT e LPC são dois métodos de análises em frequência: a Transformada Rápida de Fourier (FFT) que pode ser usada para obtenção das frequências de ressonância e da excitação do trato vocal; e a Codificação Preditiva Linear (LPC), que extrai apenas a envoltória espectral do sinal de fala, não levando em conta o sinal de excitação do trato vocal (Fo).

3 Os valores apresentados aqui são uma aproximação grosseira, visto que os valores variam muito de estudo para estudo (dependente das variações interfalantes) e entre diferentes línguas. Jesus e Shadle (2005) apresentam um bom resumo de dados, especialmente para as fricativas posteriores em diferentes línguas.
} 
como $\left[\mathrm{X}, \mathrm{b}, \mathrm{r}_{\mathrm{o}}\right]$, que são, respectivamente, as fricativas uvulares surdas e sonoras, e a fricativa alveolar surda ${ }^{4}$. Os parâmetros analisados foram as características espectrais juntamente com uma análise temporal detalhada. As conclusões dos autores são de que as frequências de picos de alta amplitude dos espectros de [x] e [ $\mathbf{b}]$ em torno de $1.0-1.6 \mathrm{kHz}, 2.8$ $\mathrm{kHz}$ e $3.2-4 \mathrm{kHz}$ indicam claramente um ponto de articulação posterior.

No topo, [s], com a menor cavidade frontal, há um pico amplo em aproximadamente $8 \mathrm{kHz}$; [j], no centro, há um pico em aproximadamente $3,5 \mathrm{kHz}$; e / $\mathrm{r} /$, realizado - como acreditamos - como [x] (abaixo), uma série de picos em 1,3 kHz, 2,4 kHz, indicando uma cavidade frontal ainda mais longa. Em todos os tokens de $[\mathrm{X}]$, ocorrem picos na faixa de 1,0 a $1,6 \mathrm{kHz}, 2,1$ a 2,8 kHz e 3,2 a $4 \mathrm{kHz}$, consistente com as descrições de outros autores das fricativas uvulares (JESUS; SHADLE, 2005, p. 35, tradução nossa) ${ }^{5}$.

A transição entre fricativa e vogal também é parâmetro importante para a análise das fricativas. Essa transição é analisada a partir da trajetória de F2 (F2 de transição ou locus acústico consonantal). $\mathrm{O}$ início de $\mathrm{F} 2$ vocálico será progressivamente mais alto à medida que a constrição recua.

O F2 de transição é medido no ponto de transição da consoante oclusiva para a vogal seguinte e está relacionado com a cavidade posterior à obstrução: quanto menor a cavidade posterior à obstrução maior será o valor do F2 de transição" (CRISTÓFARO-SILVA et al., 2019, p. 150).

As características de transição entre fricativa e vogal assemelham-se à transição entre plosiva e vogal com ponto de articulação homorgânico (BARBOSA; MADUREIRA, 2015). Assim, por exemplo, uma fricativa alveolar apresenta características transitórias semelhantes à oclusiva alveolar, e assim por diante. No caso das fricativas posteriores, a fricativa velar $[\mathrm{x}]$ teria características transitórias semelhantes a $[\mathrm{k}]$. Como a cavidade posterior é bastante reduzida para a fricativa velar, tem-se um valor de transição mais alto. O contexto vocálico também tem interferência nesses valores. Diante de vogais posteriores, a transição é mais marcada. Além disso, muitos estudos atestam que as vogais adjacentes interferem também nos valores dos picos espectrais,

\footnotetext{
4 Segundo Jesus e Shadle (2005), [r。] é produzido como uma fricativa alveolar desvozeada.

5 On top, [s], with the shortest front cavity, has a broad peak at approximately $8 \mathrm{kHz}$; [j], centre, has a peak at approximately $3.5 \mathrm{kHz}$; and $/ \mathrm{r} /$, realized - as we believe - as [x] (bottom), a series of peaks at $1.3 \mathrm{kHz}, 2.4 \mathrm{kHz}$, indicating a still longer front cavity. Across all tokens of $[\mathrm{X}]$, peaks occur in the range of $1.0-1.6 \mathrm{kHz}, 2.1-2.8 \mathrm{kHz}$ and $3.2-4 \mathrm{kHz}$, consistent with other authors' descriptions of uvular fricatives (JESUS; SHADLE, 2005, p. 35).
} 


\section{v. $10(1)$} 77-97 jan-abr 2020

além dos valores de F2 de transição. O arredondamento dos lábios, por exemplo, baixa os formantes, uma vez que provoca um alongamento do trato anterior à constrição (JOHNSON, 2003). Desse modo, é pertinente avaliarmos os efeitos da coarticulação não apenas na transição vocálica, mas também nos picos espectrais.

Stevens (1997) discute as transições de F2 e F3 na caracterização de consoantes labiais, palatais e velares em diferentes contextos vocálicos. Segundo o autor, as transições tendem a ser menos extremas para as fricativas do que para as oclusivas, embora similares. Para as fricativas produzidas na região da faringe, os movimentos formânticos são diferentes das consoantes que têm constrição no trato oral.

A diferença mais saliente é que a frequência do primeiro formante não diminui quando uma constrição faríngea é formada, uma vez que essa constrição é feita na metade posterior da função da área do trato vocal (KLATT e STEVENS, 1969). Espera-se que uma constrição na região inferior da faringe leve a um aumento maior de F1 do que uma constrição na região uvular (...) As consoantes faríngeas mostram um aumento de F3 na vogal seguinte, enquanto as uvulares não; e ambas as faríngeas e uvulares têm um aumento de F2 quando a vogal é [i] (STEVENS, 1997, p. 484, tradução nossa) ${ }^{6}$.

No entanto, a fricativa glotal não costuma estar associada a transições formânticas. Embora seja classificada como fricativa por apresentar turbulência, ela apresenta suas peculiaridades. Diferentemente de outras fricativas, ela exibe acoplamento dos tubos anterior e posterior, uma vez que a constrição se dá na glote e não no trato vocal. O espectro de [h] é como o espectro de uma vogal, embora com maior amplitude relativa dos formantes mais altos do que geralmente se vê nas vogais (JOHNSON, 2003).

A fricativa [h] tipicamente não está associada com transições formânticas. Não apenas [h] é produzida na glote e faringe, mas pode ser quase completamente coarticulada com o formato do trato vocal da vogal seguinte. Por exemplo, na palavra he, a configuração do trato vocal para a vogal [i] é assumida durante a produção da fricativa. Portanto, transições formânticas estão virtualmente ausentes, embora o segmento de ruído [h] frequentemente possua uma estrutura semelhante a um formante bem marcado (KENT; READ, 2015, p. 274).

\footnotetext{
${ }^{6}$ The most salient difference is that the first-formant frequency does not decrece when a pharyngeal constriction is formed, since such a constriction is made in the posterior half of the vocal-tract area function (KLATT and STEVENS, 1969). A constriction in the lower pharyngeal region is expected to cause a greater increase in $\mathrm{F} 1$ than a constriction in the uvular region (...) Pharyngeal consonants show a rising F3 into the following vowel whereas uvulars do not, and both pharyngeals and uvulars have a rising F2 when the vowel is [i] (STEVENS, 1997, p. 484).
} 
Momentos espectrais7, como centro de gravidade, variância, assimetria e curtose, como já mencionado na introdução, são critérios usados em algumas pesquisas (CRISTOFOLINI, 2013; FERREIRA-SILVA; PACHECO; CAGLIARI, 2015, por exemplo) para distinguir as fricativas anteriores entre si. No entanto, não encontramos nenhum estudo que observasse esses parâmetros para distinguir as fricativas posteriores.

Outros parâmetros discutidos nos estudos sobre fricativas são a duração e a amplitude (JESUS, 2000; FERREIRA-SILVA; PACHECO, 2012). A duração tem se mostrado um parâmetro válido para distinguir fricativas sonoras das surdas, sendo as sonoras, em média, mais curtas do que as surdas homorgânicas (JESUS, 2000). Essa diferença de duração "relaciona-se à dificuldade de produção das sonoras: o fluxo de ar dos pulmões deve ser suficiente para fazer vibrar as pregas vocais e ainda ter velocidade de fluxo de ar para gerar a turbulência necessária à fricção" (BARBOSA; MADUREIRA, 2015, p. 408). Em relação à amplitude, sabemos que esta cai à medida que a constrição recua. Desse modo, fricativas posteriores têm menos energia do que as anteriores, e dentre delas, a glotal é a que tem menos energia. Nas Figuras 1 e 2, podemos visualizar, no espectrograma, como a fricativa glotal apresenta menos energia do que a velar ${ }^{8}$. No entanto, nenhum estudo sistemático, até o momento, foi conduzido para determinar a magnitude das diferenças de amplitude em função do local de articulação.

Figura 1 - Fricativa velar $[\mathrm{x}]$ na palavra "terra"

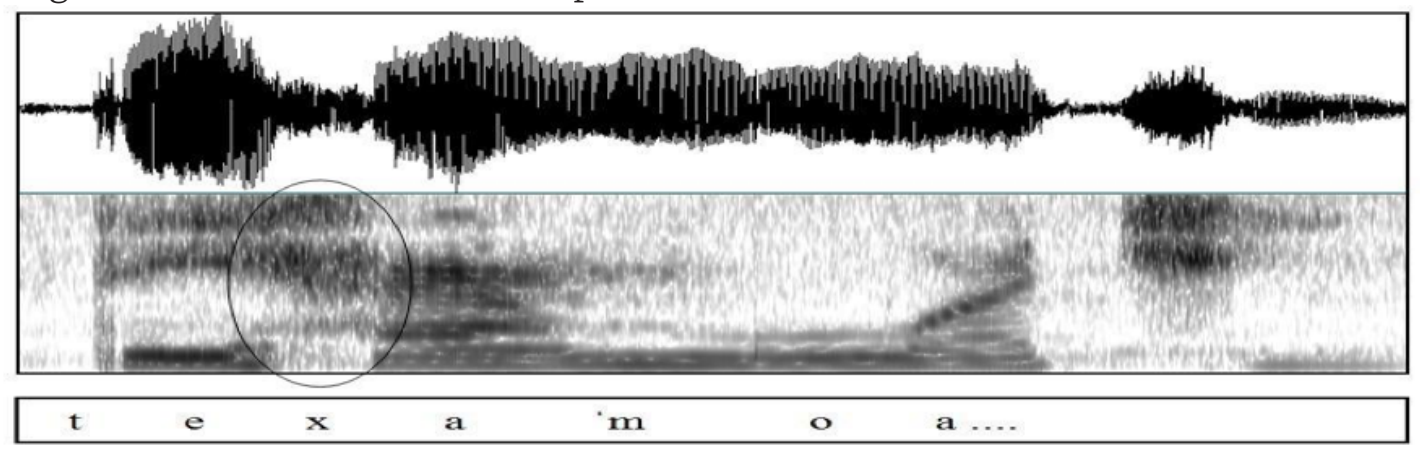

Fonte: Bueno (2013).

\footnotetext{
${ }^{7}$ Momentos espectrais trazem informações mais globais do espectro em frequência e referemse a métricas quantitativas baseadas na análise estatística do espectro.

${ }^{8}$ Essa classificação foi dada pela autora indicada na fonte da figura. Em seu estudo, os dados foram classificados de oitiva e a verificação acústica foi utilizada para confirmar casos duvidosos a partir de uma análise qualitativa de observação de forma de onda e espectro.
} 
v. $10(1)$ 77-97 jan-abr 2020

Figura 2 - Fricativa glotal [h] na palavra "cachorro"

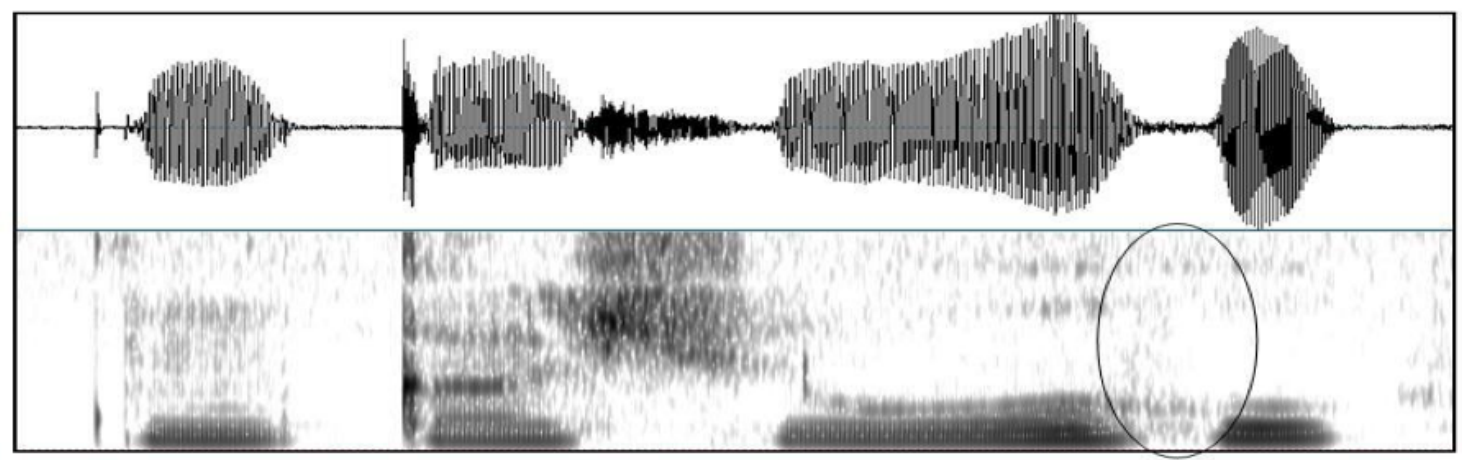

\begin{tabular}{|llllll|}
\hline$\ldots \mathrm{k}$ & $\mathrm{a}$ & $\mathrm{J}$ & $\mathrm{o}$ & $\mathrm{h}$ & $\mathrm{u}$ \\
\hline
\end{tabular}

Fonte: Bueno (2013).

Considerando o exposto, vemos que a caracterização das fricativas posteriores ainda carece de estudos mais sistemáticos para estabelecermos parâmetros acústicos que possam identificá-las. Com a revisão da literatura aqui realizada, surgiram as seguintes perguntas de pesquisa: as análises das imagens ultrassonográficas evidenciarão diferentes fricativas posteriores? Os parâmetros picos espectrais, média espectral (centrodegravidade) eamplitudeexibirão diferenças relacionadas às diferentes fricativas posteriores produzidas? Partimos das hipóteses de que as imagens ultrassonográficas mostraram comportamentos característicos relacionados às diferentes fricativas produzidas. E ainda os picos espectrais serão mais altos para fricativas velares do que para as glotais e, quanto mais recuada for a fricativa, menos amplitude ela terá. Essas perguntas de pesquisa e hipóteses guiam o nosso roteiro de análise, que será descrito a seguir na metodologia. Observamos, todavia, que nossos dados são restritos e podem ser considerados apenas como um passo inicial para responder a essas questões.

\section{Metodologia}

Propomos, neste trabalho, um estudo inicial sobre as fricativas posteriores a partir de produções de duas informantes femininas. As informantes encontram-se na mesma faixa etária (em torno de 20 anos) e são estudantes universitárias. Elas são naturais de Florianópolis, SC. Outras gravações foram feitas anteriormente, com outros informantes, mas foram descartadas pela má qualidade das imagens.

O corpus é composto de palavras reais (Rita, rato) e de pseudopalavras, palavras que não fazem parte do léxico da língua portuguesa, como (arru), conforme Quadro 1. 
Quadro 1 - Lista de palavras lidas por cada informante9

\begin{tabular}{|c|c|}
\hline Informante 1 & Informante 2 \\
\hline Rato & Rato \\
Rita & Rita \\
Ruga & Ruga \\
Enxurrada & Arra \\
Garrafa & Arri \\
Birra & Arru \\
Barra & Irra \\
& Irri \\
& Urra \\
\hline
\end{tabular}

Fonte: Elaborado pelas autoras.

As informantes repetiram 5 vezes cada palavra do corpus, totalizando 85 produções. O tipo de coleta, no entanto, foi diferente para cada uma delas: a Informante 1 leu apenas palavras reais inseridas em frases-veículo, e a Informante 2 leu palavras reais e pseudopalavras isoladas, sem o apoio de uma frase-veículo. As duas coletas também se deram em períodos diferentes. Foi somente após a análise preliminar da Informante 1 que coletamos os dados da Informante 2. Foi também a partir dessa análise que sentimos a necessidade de inserir pseudopalavras para analisar melhor os contextos vocálicos. Nesse estudo, limitamonos a discutir os contextos de [a], [i] e [u].

A gravação de áudio foi feita simultaneamente com a coleta de vídeos ultrassonográficos. Os equipamentos para os vídeos ultrassonográficos foram os seguintes: microfone oral (headworn Shure); ultrassom Mindray M5 com sonda endocavitária (6CV1S); capacete de estabilização de movimentos e sincronizador de imagem e áudio (SBU 1.0). Os dados de áudio foram gravados em outro computador, com hardware MOTU UltraLite mk3, numa taxa de amostragem de $44 \mathrm{kHz}$. A Informante 1 usou o microfone, marca e modelo Shure WH2OXLR, posto em sua frente num pedestal. A Informante 2 usou o microfone, marca e modelo Audio-technica PRO 8HEx, fixo no capacete de estabilização. Toda coleta foi feita em cabine com isolamento acústico.

Começamos a análise dos dados com os vídeos de ultrassonografia. Estes foram observados e manejados com o programa AAA (Articulate Assistant Advanced), versão 2.17.06. Para essa análise, consideramos o ponto máximo de constrição da fricativa e da vogal seguinte e, após traçarmos os contornos da língua nessas posições, comparamos as configurações das fricativas e das vogais.

\footnotetext{
${ }_{9}$ Como esta é uma pesquisa de análises ultrassonográficas ainda inicial, estamos testando o tipo de corpus a ser lido pelas informantes. Por essa razão, a lista de palavras lida por cada uma delas não é exatamente a mesma.
} 
v. $10(1)$ 77-97 jan-abr 2020

Depois da análise articulatória dos sons fricativos produzidos a partir das imagens ultrassonográficas, seguimos para a análise acústica com base nos áudios gravados, observando os seguintes parâmetros:

Picos espectrais: região de frequência com maior amplitude, visualizada a partir de espectros de FFT e da coleta automatizada via script de F1, F2 e F3 de cinco pontos equidistantes na região de produção do segmento. Esperamos que os picos espectrais se deem em regiões cada vez mais baixas à medida que a constrição recua.

Centro de gravidade: média da frequência dos picos espectrais, extraídos a partir do FFT da parte central da fricativa. O objetivo desse procedimento é comparar a influência das vogais adjacentes, uma vez que vogais posteriores alongam o trato anterior à constrição, levando à queda das frequências dos formantes da fricativa.

Amplitude: amplitude total da fricativa foi analisada apenas para a Informante 2, uma vez que, para esta informante, temos um conjunto de dados mais homogêneos, apenas com palavras dissílabas. Além disso, outro fator que motivou a exclusão da análise dos dados da Informante 1 foi o fato de não termos o microfone acoplado ao capacete, 0 que pode acarretar diferenças de amplitude em decorrência de alterações de distância em relação ao microfone. A tonicidade será considerada nessa análise, uma vez que a Informante 2 leu todas as pseudopalavras como paroxítonas, ou seja, a fricativa ficou em sílaba átona, diferentemente do que ocorre nas palavras reais, nas quais a fricativa se encontra em sílaba tônica. Esperamos encontrar amplitudes mais baixas à medida que a constrição recua, independentemente da tonicidade.

Apesar do número pequeno de dados, eles foram suficientes para uma análise estatística inferencial preliminar. Assim, submetemos os resultados referentes aos picos espectrais, centro de gravidade e amplitude a tratamento estatístico para verificar se houve significância nas diferenças encontradas. Nesse caso, usamos o teste Anova, calculado no One Way Anova Calculator ${ }^{10}$, usando uma margem de significância de 0,05. A seguir, passamos para a descrição dos dados e discussão dos resultados.

\section{Análise articulatória dos dados}

Para a análise articulatória das fricativas produzidas, em todas as imagens de vídeo observamos o ponto de máxima constrição da fricativa e da vogal, sobrepondo esses traçados. Nesses traçados de

${ }^{10}$ Disponível em: https://www.socscistatistics.com/tests/anova/default2.aspx 
língua mostrados no decorrer deste texto, a raiz da língua localizase à esquerda e a ponta, à direita. A seguir, na Figura 3, ilustramos o movimento de uma fricativa velar, com elevação do dorso da língua, e uma fricativa faringal, com movimento da raiz da língua. As setas indicam esses movimentos.

Figura 3 - Ponto máximo de constrição da fricativa - à esquerda, constrição velar; à direita, constrição faringal
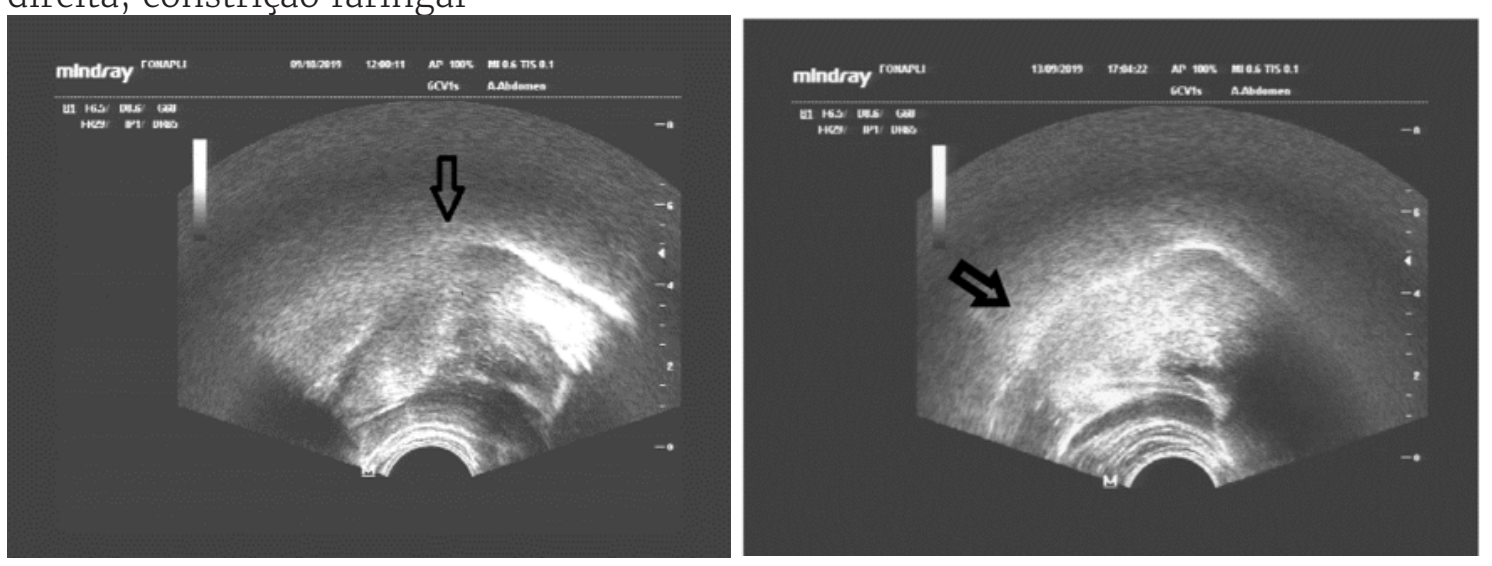

Fonte: Elaborada pelas autoras.

Nas Figuras 4 e 5, sobrepomos os pontos de constrição máxima das vogais adjacentes e da fricativa. As linhas azuis são referentes à posição da língua nos frames $^{11}$ da fricativa; as linhas vermelhas correspondem à posição da língua nos frames da vogal.

Figura 4 - Sobreposição dos movimentos da fricativa (linha vermelha) e da vogal seguinte (linha azul) de uma velar, à esquerda, na palavra enxurrada; e uma faringal, à direita, na palavra arra

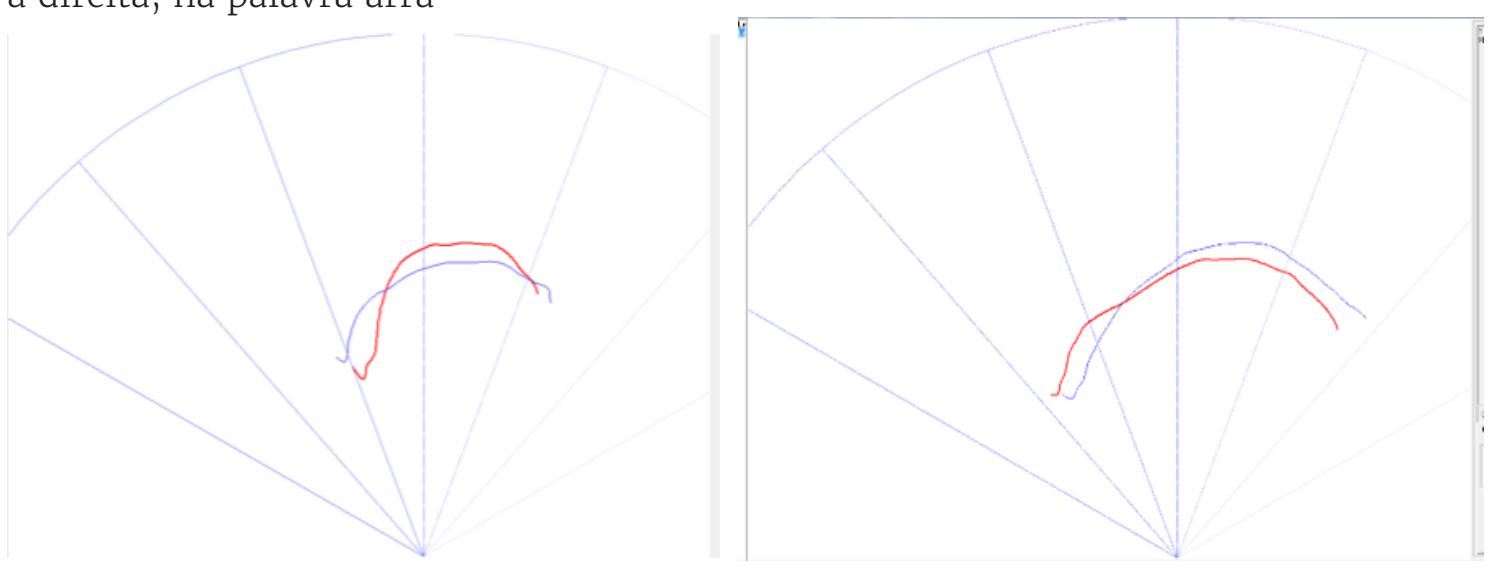

Fonte: Elaborada pelas autoras.

${ }^{11}$ Frame é um quadro de vídeo, ou seja, é cada uma das imagens fixas de um produto audiovisual. Quanto maior o número de quadros, melhor a qualidade de imagem do vídeo. 


\section{v. $10(1)$} 77-97 jan-abr 2020

Figura 5 - Sobreposição dos movimentos da vogal adjacente (linha azul) e da fricativa (linha vermelha) na produção de uma glotal na palavra rato

Fonte: Elaborada pelas autoras.

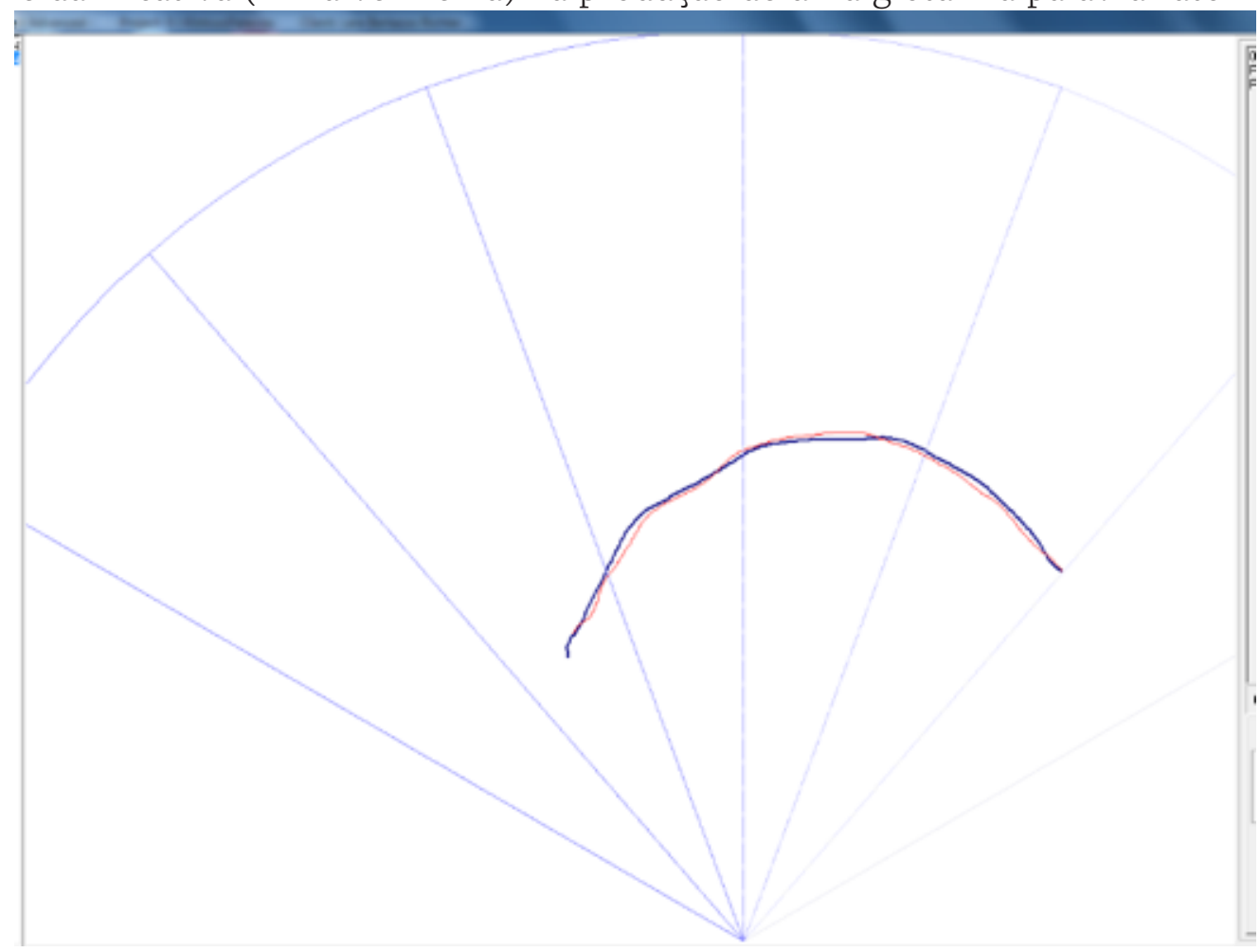

88

Comparando as Figuras 4 e 5, observamos que, na primeira, há deslocamento no ponto de constrição máxima da fricativa em relação à vogal consecutiva, evidenciando constrição no trato oral (velar) e na faringe (faringal). Já na figura 5, observamos que os pontos de constrição da vogal adjacente seguinte e da fricativa se sobrepõem, evidenciando que não houve nenhuma constrição no trato para a produção da fricativa, ou seja, trata-se de uma fricativa glotal.

A partir das análises das imagens ultrassonográficas, parecenos possível dizer que encontramos fricativas velares, faringais e glotais nos dados das duas informantes. Outro fato interessante observado a partir dos totais de ocorrência das fricativas por palavra, mostrado na Tabela 1, foi que a vogal parece ser condicionadora do tipo de fricativa, uma vez que as faringais sempre ocorreram em contexto de vogal antecedente [a], as velares ocorreram apenas quando a fricativa era seguida de [a] e, nos demais contextos vocálicos, [i, u], ocorreu sempre uma glotal. Também é importante salientar as diferenças interindividuais: apenas uma informante produziu fricativa faringal; enquanto a outra produziu apenas velares para o contexto vocálico de [a]. 
Tabela 1 - Totais de ocorrências de fricativas por palavra

\begin{tabular}{|l|l|l|l|l|l|}
\hline \multicolumn{2}{|l|}{ Velares } & Faringais & \multicolumn{1}{l|}{ Glotais } \\
\hline \multicolumn{1}{|c|}{ Palavra } & $\%$ & Palavra & $\%$ & Palavra & \multicolumn{1}{c|}{$\%$} \\
\hline Rato & 8,23 & Arra & 5,88 & Rato & 3,52 \\
Garrafa & 5,88 & Arri & 5,88 & Rita & 11,76 \\
Barra & 5,88 & Arru & 3,52 & Ruga & 11,76 \\
Enxurrada & 5,88 & & Urra & 5,88 \\
& & & Arru & 2,35 \\
& & & Urru & 5,88 \\
& & & Irra & 5,88 \\
& & & Birra & 5,88 \\
& & & Irri & 5,88 \\
\hline
\end{tabular}

Fonte: Elaborada pelas autoras.

Passemos às análises dos parâmetros acústicos.

\section{Análise acústica dos dados}

Como os dados foram gravados com diferentes metodologias, apresentamos os resultados separadamente para cada informante.

Na análise acústica dos dados produzidos pela Informante 1, apresentados na Tabela 2, percebe-se que houve uma certa variabilidade nos picos, como podemos verificar pelos valores do desvio padrão.

Tabela 2 - Picos espectrais e centro de gravidade por palavra da Informante 1

\begin{tabular}{|l|l|l|l|l|}
\hline \multirow{3}{*}{ Fricativa } & Palavra & \multicolumn{2}{|l|}{ Pico espectral } & Centro de \\
\cline { 3 - 5 } & & Média & $\begin{array}{l}\text { Desvio } \\
\text { padrão }\end{array}$ & \\
\hline \multirow{4}{*}{ Velar } & Rato & 1202 & 101,09 & 1284 \\
\cline { 2 - 5 } & Garrafa & 1702 & 247,83 & 1482 \\
\cline { 2 - 5 } & Barra & 1694 & 255,94 & 1041 \\
\cline { 2 - 5 } & Enxurrada & 1660 & 117,24 & 1165 \\
\hline \multirow{3}{*}{ Glotal } & Rita & $340 / 2631$ & $94,25 / 455,97$ & 838 \\
\cline { 2 - 5 } & Birra & $298 / 2037$ & $58,65 / 124,99$ & 810 \\
\cline { 2 - 5 } & Ruga & 701 & 125,65 & 664 \\
\hline
\end{tabular}

Fonte: Elaborada pelas autoras.

Pela Tabela 2, podemos observar um comportamento aparentemente diferente entre os valores das fricativas velares e das fricativas glotais. Os picos espectrais das velares ficam em torno de 1.2 - $1.6 \mathrm{kHz}$. As glotais, no entanto, parecem ter seus picos espectrais relacionados às vogais adjacentes seguintes. Para a palavra 
v. 10 (1) 77-97 jan-abr 2020

Rita, verificamos um primeiro pico em frequência bastante baixa, correspondente ao valor de F1 da vogal [i] e um outro pico em torno de 2 kHz. A Figura 6 mostra essa sobreposição, que não ocorre na consoante velar, visualizada na Figura 7.

Figura 6 - Picos espectrais da vogal [i] (linha vermelha) e da fricativa glotal (linha preta) da palavra Rita, da Informante 1

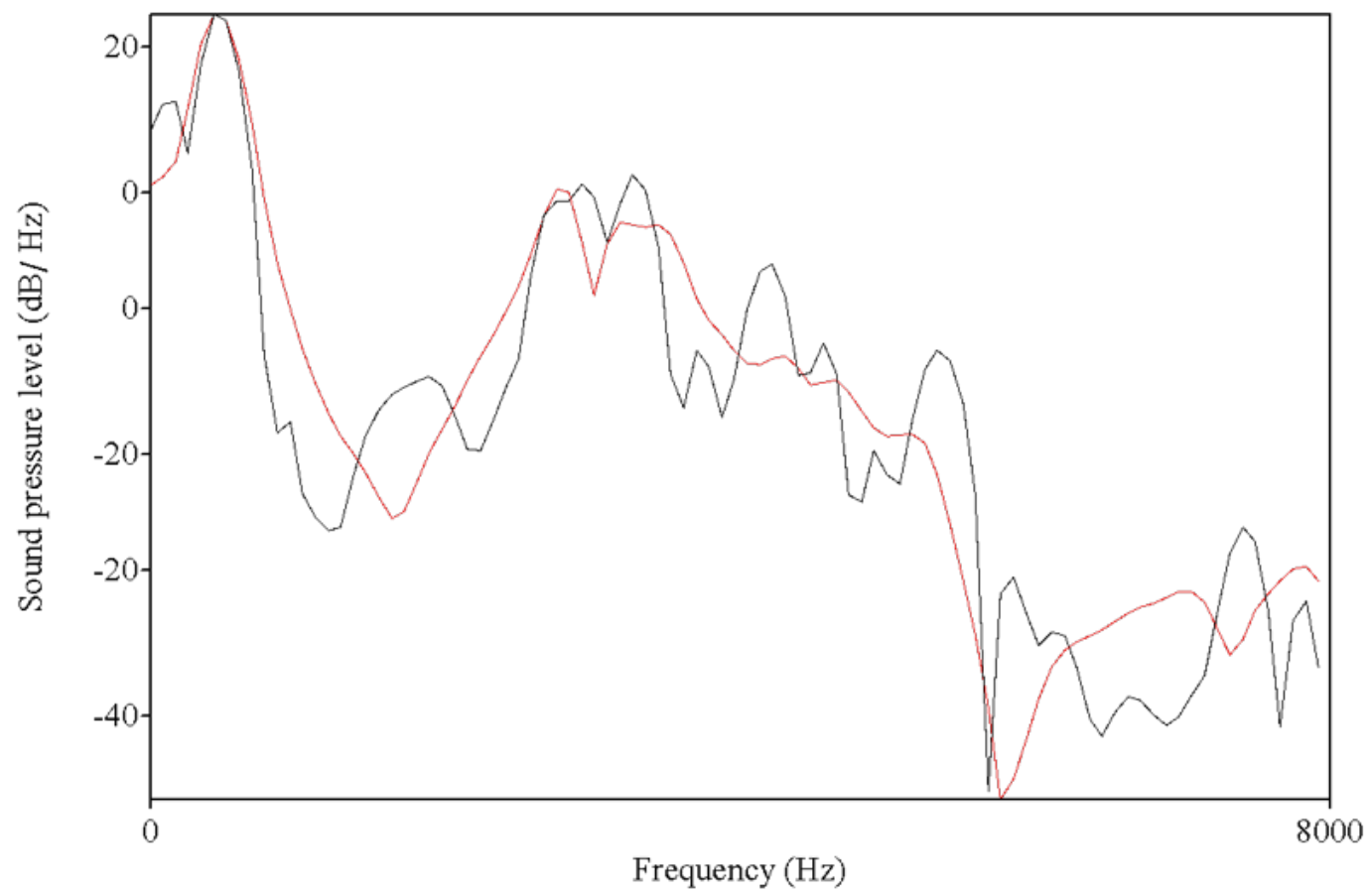

Fonte: Elaborada pelas autoras.

Figura 7 - Picos espectrais da vogal [a] (linha vermelha) e da fricativa velar (linha preta) da palavra garrafa, da Informante 1

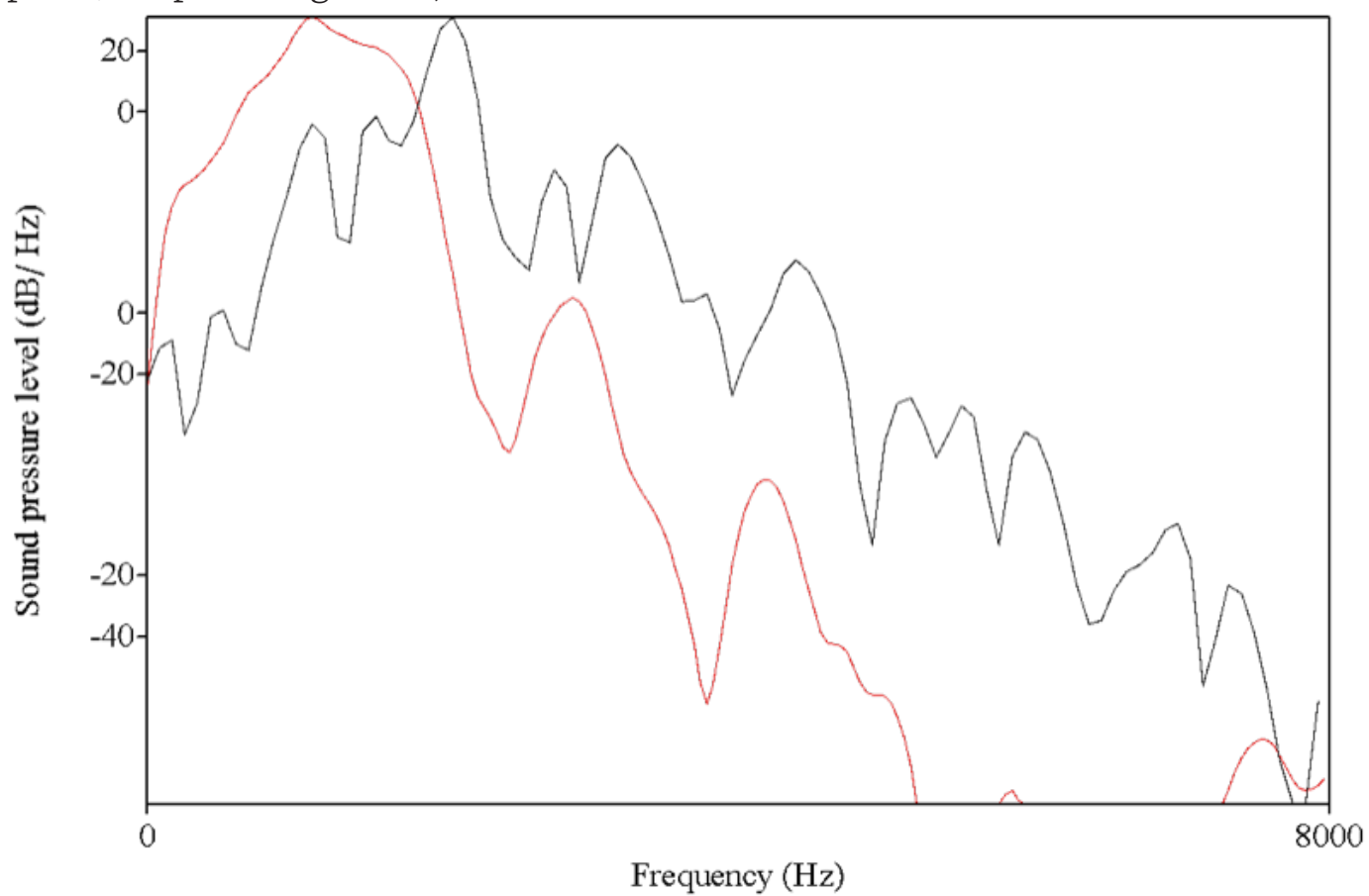

Fonte: Elaborada pelas autoras. 
Para a palavra ruga, o pico corresponde ao F1 da vogal [u]. A palavra birra, embora seguida de [a], manteve os picos correspondentes à vogal antecedente [i], possivelmente pela atonicidade da vogal final. Todavia, para a Informante 1 , devido ao número reduzido de dados e por não haver distribuição de diferentes fricativas nos diferentes contextos vocálicos, não aplicamos nenhum teste estatístico. Os dados da Informante 2 são em maior número e nos permitiram análises estatísticas inferenciais preliminares e juntamente com os resultados apresentados pela Informante 1, certamente auxiliarão nas conclusões sobre o comportamento dos parâmetros acústicos relacionados às fricativas posteriores.

Tabela 3 - Picos espectrais e centro de gravidade por palavra da Informante 2

\begin{tabular}{|l|l|l|l|l|}
\hline \multirow{2}{*}{ Fricativa } & \multirow{2}{*}{ Palavra } & \multicolumn{2}{|l|}{ Pico espectral } & Centro de \\
\cline { 2 - 5 } & & Média & Desv. padrão & \\
\hline \multirow{2}{*}{ Velar } & Rato & 1076 & 14,84 & 1867 \\
\hline \multirow{5}{*}{ Faringal } & Arra & 1129 & 68,43 & 1612 \\
\cline { 2 - 5 } & Arri & 1055 & 84,73 & 1884 \\
\cline { 2 - 5 } & Arru & 1026 & 4,24 & 1102 \\
\hline \multirow{5}{*}{ Glotal } & Rato & 1129 & 42,5 & 1878 \\
\cline { 2 - 5 } & Irra & 2139 & 252,12 & 1926 \\
\cline { 2 - 5 } & Urra & 1180 & 133,87 & 1083 \\
\cline { 2 - 5 } & Rita & 2903 & 302,61 & 3050 \\
\cline { 2 - 5 } & Irri & 2923 & 96,89 & 3120 \\
\cline { 2 - 5 } & Ruga & 964 & 27,84 & 913 \\
\cline { 2 - 5 } & Urru & 654 & 166,03 & 729 \\
\cline { 2 - 5 } & Arru & 1087 & 73,9 & 1466 \\
\hline
\end{tabular}

Fonte: Elaborada pelas autoras.

Para a Informante 2, cujos dados são exibidos na Tabela 3, encontramos consistência nos dados em relação aos contextos vocálicos, considerando os valores baixos de desvio padrão ${ }^{12}$. No entanto, a mesma consistência não foi observada para os diferentes tipos de fricativas, uma vez que encontramos valores de picos espectrais mais altos para glotais do que para as velares. As fricativas glotais têm picos compatíveis com os formantes da vogal seguinte, uma vez que não há uma configuração do trato vocal específico para a glotal, e sim, a configuração do trato

\footnotetext{
${ }^{12}$ Os dados com alto desvio padrão: Rita: picos em torno de $2700-2900 \mathrm{~Hz}$, dado discrepante - pico de $3341 \mathrm{~Hz}$; Urru: picos em torno de 650-760, dado discrepante: pico em $366 \mathrm{~Hz}$; Irra: picos entre 1900-2200 Hz, pico discrepante: $2508 \mathrm{~Hz}$; Urra: dados variam gradativamente entre 1066 até $1363 \mathrm{~Hz}$.
} 


\section{10 (1)} 77-97 jan-abr 2020

vocal para a produção da vogal. O mesmo não acontece para as fricativas faringais, para as quais a média do pico espectral parece ser decorrente da constrição, uma vez que não há diferenças significativas nos três contextos vocálicos $(\mathrm{p}=0.245)$.

A Figura 8 evidencia a sobreposição dos picos/formantes da vogal (linha vermelha) e da fricativa (linha preta) nos contextos de vogal seguinte [i], o que não acontece com a consoante faringal, conforme vemos na Figura 9.

Figura 8 - Picos espectrais da vogal [i] (linha vermelha) e da fricativa glotal (linha preta) da palavra Rita, da informante 2

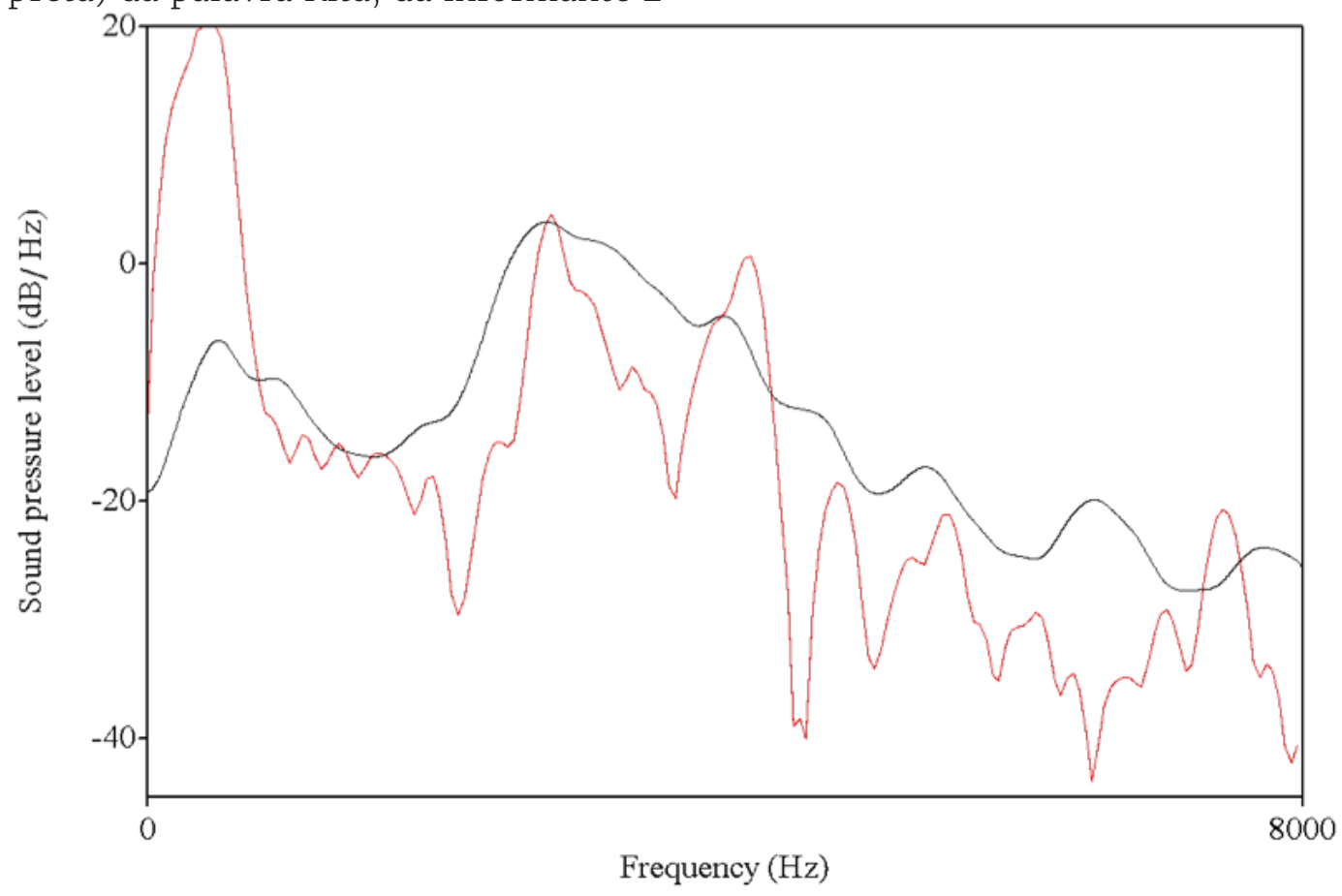

Fonte: Elaborada pelas autoras. 
Figura 9 - Picos espectrais da vogal [i] (linha vermelha) e da fricativa faringal (linha preta) da palavra arri, da informante 2

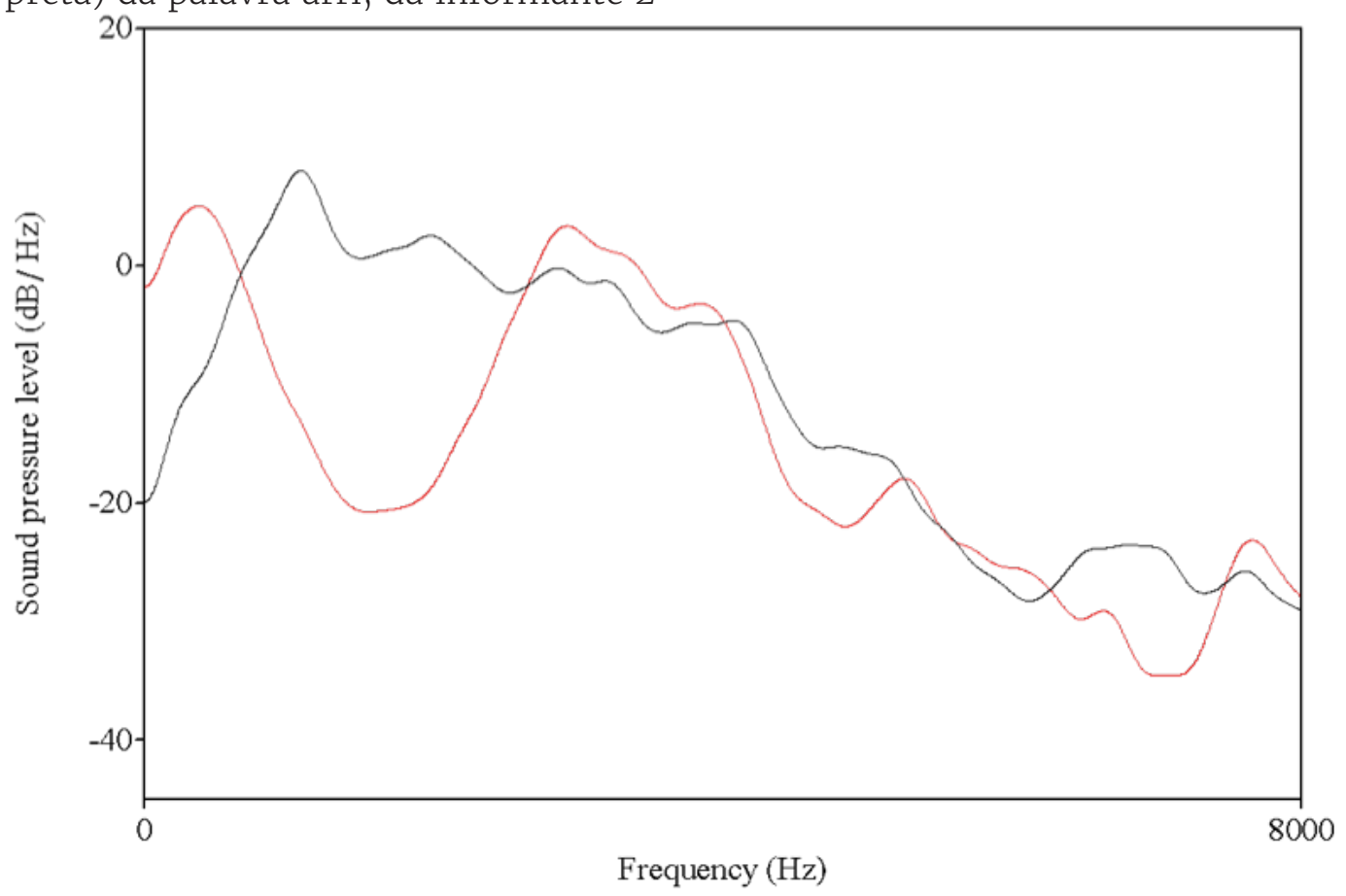

Fonte: Elaborada pelas autoras.

Nos dados da Informante 2, diferentemente dos da Informante 1, os picos de maior amplitude das fricativas glotais correspondem, na maioria das vezes, ao F2 da vogal. Houve também picos mais fracos, em frequências mais baixas, correspondente ao F1 das vogais. Esse efeito de sobreposição do pico espectral ao F1 ou F2 da vogal seguinte é consistente quando a fricativa está em início de palavra ou quando está entre duas vogais iguais. No caso de vogais diferentes, como em urra e irra, temos valores diferentes para os picos espectrais, a depender da zona de transição entre as vogais sobreposta à fricção no ponto que marcamos para extrair o FFT da fricativa, evidenciando também a influência da vogal antecedente.

O centro de gravidade varia de acordo com a vogal que segue a fricativa. As fricativas seguidas de [i] têm seu centro de gravidade mais alto se comparadas às seguidas de [a], que, por sua vez, têm o centro de gravidade mais alto do que aquelas seguidas de [u]. É possível observar que a vogal antecedente também tem seu efeito. Observemos as palavras urra e irra: ambas seguidas de [a], no entanto, os valores do centro de gravidade são mais altos para irra do que para urra, e essa diferença foi estatisticamente relevante $(p=0,003)$. Vale lembrar que, nas glotais, a variação dos picos espectrais está diretamente ligada às vogais adjacentes, o que explica uma média mais alta para [i], em que tanto o F2 quanto o F3 passam de $2000 \mathrm{~Hz}$, o que não acontece com as demais vogais. 
V. $10(1)$

77-97

jan-abr 2020

No grupo das fricativas faringais, novamente confirmamos a significância da relação com as vogais: o centro de gravidade resultou em diferença estatisticamente significante $(\mathrm{p}=0.000018)$ para as três vogais, nas palavras arra, arri e arru.

Quanto à diferenciação de velares e faringais, comparamos os picos espectrais das duas informantes. A diferença foi significativa $(\mathrm{p}=$ 0,00001), ou seja, os picos espectrais estão em frequências mais altas para as velares do que para as faringais. No entanto, cabe a ressalva de que há diferenças individuais, como extensão do trato vocal, que podem interferir nesse resultado, além de um conjunto diferente de palavras. Para maiores generalizações, convém um número maior de dados.

Outro parâmetro analisado foi a amplitude. Para esse parâmetro, avaliamos apenas os dados da Informante 2, uma vez que a distância entre trato vocal e o microfone foi mantida constante devido ao uso do microfone acoplado ao capacete do ultrassom. A Tabela 4 resume os resultados referentes ao parâmetro amplitude das fricativas produzidas pela Informante 2. Para essa informante, os valores do coeficiente de variação $(\mathrm{CV})$ parecem mostrar pouca variabilidade em torno da média.

Tabela 4 - Média e desvio padrão de amplitude por palavra da Informante 2

\begin{tabular}{|c|c|c|c|c|}
\hline \multirow[t]{2}{*}{ Fricativa } & \multirow[t]{2}{*}{ Palavra } & \multicolumn{3}{|c|}{ Amplitude (dB) } \\
\hline & & Média & Desv. padrão & CV (\%) \\
\hline Velar & Rato & 42 & 2,82 & 6,72 \\
\hline \multirow[t]{3}{*}{ Faringal } & Arra & 42 & 3,27 & 7,79 \\
\hline & Arri & 40 & 3,28 & 8,20 \\
\hline & Arru & 38 & 2,54 & 6,68 \\
\hline \multirow[t]{7}{*}{ Glotal } & Rato & 42 & 0,57 & 1,36 \\
\hline & Irra & 37 & 2,54 & 6,86 \\
\hline & Urra & 37 & 2 & 5,40 \\
\hline & Rita & 36 & 2,28 & 6,33 \\
\hline & Irri & 36 & 2,54 & 7,06 \\
\hline & Ruga & 32 & 2,16 & 6,75 \\
\hline & Urru & 34 & 3,97 & 11,68 \\
\hline
\end{tabular}

Fonte: Elaborada pelas autoras.

As diferenças foram significativas entre as faringais e as glotais ( $\mathrm{p}=0,00003$ ), ou seja, a amplitude é um parâmetro capaz de distinguir as fricativas em questão, sendo as glotais as mais fracas, como atestado pela literatura (JESUS, 2000). A tonicidade da sílaba em que se encontra a fricativa não exerceu efeitos significativos sobre a 
amplitude $(\mathrm{p}=0,952)$, resultado que pode ser atribuído ao fato de as palavras terem sido lidas isoladamente, em contexto artificial de fala. Dados espontâneos e em maior quantidade poderão confirmar se a tonicidade tem influência sobre a amplitude das fricativas posteriores.

\section{Considerações finais: avanços e limitações}

O presente trabalho foi um estudo inicial da caracterização articulatória e acústica de fricativas posteriores na posição de onset silábico. A análise ultrassonográfica se mostrou bastante útil para a identificação desses segmentos para os quais ainda não há muitos estudos quer acústicos ou articulatórios que nos deem pistas seguras para identificação de cada fricativa. No decorrer das coletas, chegamos à conclusão de que, para as investigações articulatórias, uma gravação mais controlada com palavras isoladas, por exemplo, parece ser a melhor opção para a análise segmental, evitando efeitos comuns na fala menos controlada e até mesmo em frases-veículo, como diferentes velocidades de fala e apagamentos de segmentos.

Nesse sentido, concluímos que muito mais dados são necessários para podermos fazer generalizações mais contundentes. No entanto, podemos já apontar alguns indícios: há possibilidade de constrições na laringe (fricativas faringais), além da constrição no trato oral (fricativas velares); há diferenças interindividuais do tipo de fricativa que é realizada num mesmo contexto; as vogais influenciam o tipo de fricativa a ser produzido pelo falante, sendo a vogal [a] ${ }^{13} \mathrm{a}$ condicionadora para fricativas que não sejam glotais; as medidas do centro de gravidade evidencia a influência do contexto vocálico nos picos espectrais, apresentando médias mais baixas para as vogal posterior e mais altas para a vogal anterior; os segmentos glotais assumem características espectrais da vogal seguinte, conforme explicitado por Kent e Read (2015); a amplitude também pode ser um parâmetro válido para diferenciar as fricativas posteriores entre si.

Em relação aos estudos já realizados, conforme descrito na seção teórica, vemos que os nossos resultados em relação aos picos espectrais e amplitude estão em consonância, uma vez que as fricativas velares apresentaram picos espectrais mais altos do que as faringais, e as glotais assumiram características vocálicas. A amplitude foi mais

${ }^{13}$ No momento, só podemos atribuir essa característica à vogal [a], pois não estudamos todos os contextos vocálicos. 
V. 10 (1) 77-97 jan-abr 2020

baixa para as fricativas glotais, ou seja, quanto mais posteriores, menos amplitude, confirmando, assim uma de nossas hipóteses. Devido ao conjunto de dados restrito, novos estudos devem ser empreendidos, a fim de compreender melhor esses parâmetros, além de outros, como a duração e a transição formântica, e ainda avaliar como se dá o comportamento dessas fricativas em outros contextos vocálicos.

\section{Referências}

BARBOSA, P. A.; MADUREIRA, S. Manual de fonética acústica experimental: aplicações aos dados do português. Cortez: São Paulo, 2015.

BOTASSINI, J. O. M. A variação no uso dos róticos em Porto Alegre. Estudos Linguísticos, São Paulo, v. 2, n. 40, p. 1006-1072, mai-ago. 2011.

BRESCANCINI, C.; MONARETTO, V. N. de O. Os róticos no sul do Brasil: panorama e generalizações. Signum: Estudos da Linguagem, Londrina, v. 2, n. 11, p. 51-66, dez. 2008.

BUENO, L. F. Os róticos do português falado em Brasília por crianças de 03 a 07 anos de idade. 2013. 127 f. Dissertação (Mestrado em Linguística) - Programa de Pós-Graduação em Linguística, Universidade de Brasília, Brasília, 2013.

CORRÊA, A. P. dos S. Aquisição fonológica de fricativas por crianças com transtorno fonológico: uma investigação acústica. 2013. 92 f. Dissertação (Mestrado em Estudos Linguísticos) - Instituto de Biociências, Letras e Ciências Exatas, Universidade Estadual Paulista Julio de Mesquita Filho, São Paulo, 2013.

CRISTOFOLINI, C. Gradiência na fala infantil: caracterização acústica de segmentos plosivos e fricativos e as evidências de um período de "refinamento articulatório". 2013. 286 f. Tese (Doutorado em Linguística) - Programa de Pós-Graduação em Linguística, Universidade Federal de Santa Catarina, Florianópolis, 2013.

CRISTÓFARO-SILVA, T. et al. Fonética Acústica: os sons do Português Brasileiro. São Paulo: Contexto, 2019.

FERREIRA-SILVA, A.; PACHECO, V. Características da duração do ruído das fricativas de uma amostra do Português Brasileiro. Estudos da Língua(gem). Vitória da Conquista, v. 10, n. 1, p. 9-29, jun. 2012.

FERREIRA-SILVA, A.; PACHECO, V.; CAGLIARI, L. C. Descritores estatísticos na caracterização das fricativas do Português Brasileiro: Características espectrais das fricativas. Acta Scientiarum. Language and Culture, Maringá, v. 37, n. 4, p. 371-379, out./dez. 2015.

HORA, D., MONARETTO, V. N. de O. Enfraquecimento e apagamento de róticos. In: HORA, D; COLLISCHONN, G. (Orgs.). Teoria Linguística: Fonologia e outros temas. João Pessoa: Editora Universitária, 2003. p. 114-143.

JESUS, L. M. T.; SHADLE, C. H. Acoustic analysis of European Portuguese uvular $[\mathrm{X}, \mathrm{b}]$ and voiceless tapped alveolar $\left[\mathrm{r}_{0}\right]$ fricatives. Journal of the International Phonetic Association, v. 35, n. 1, p. 27-44, 2005. 
JESUS, L. M. T. de. Acoustic Phonetics of European Portuguese Fricative

Consonants. 2000. 256 f. Tese. Department of Electronic and Computer Science, University of Southampton, Southampton,UK, 2000.

JOHNSON, K. Acoustic and auditory phonetics. 2. Oxford: Ed. Blackwell Publishing, 2003.

JONGMAN, A. et al. Acoustic characteristics of English fricatives. Journal of the Acoustical Society of America. n. 108, p. 1252-1263, 2000.

KENT, R. D.; READ, C. Análise acústica da fala. Tradução Alexsandro Rodrigues Meireles. São Paulo: Cortez, 2015.

LADEFOGED, P.; MADDIESON, I. The sounds of the words's language. Blackwell Publishers: Oxford, 1996.

REINECKE, K. Os róticos intervocálicos na gramática individual de falantes de Blumenau e Lages. 2006. 241 p. Tese (Doutorado em Linguística)-Programa de Pós-Graduação em Linguística, Universidade Federal de Santa Catarina, 2006.

RENNICKE, I. E. Variation and Change in the Rhotics of Brazilian Portuguese. Belo Horizonte, UFMG, 2015. Tese (Doutorado em Estudos Linguísticos) do Programa de Pós-Graduação em Estudos Linguísticos, Faculdade de Letras, UFMG, Belo Horizonte, 2015.

SILVA, A. H. P. As fronteiras entre Fonética e Fonologia e a alofonia dos rótico iniciais em PB: dados de dois informantes do sul do país. Campinas, UNICAMP, 2002. Tese (Doutorado em Linguística) do Programa de Pós-graduação em Linguística do Instituto de Estudos da Linguagem, UNICAMP, Campinas, 2002.

SILVA, A. F. da. Estudo das características acústicas das fricativas do português do Brasil. 2012. 106 f. Dissertação (Mestrado em Linguística e Língua Portuguesa) - Universidade Estadual Paulista, Faculdade de Ciências e Letras, Campus de Araraquara, 2012.

STEVENS, K. Articulatory-acoustic-auditory relationships. In: HARDCASTLE, W.J. \& LAVER, J. The handbook of phonetic sciences. Massachusetts: Blackwell, 1997. p. 462-506. 